\title{
The Influence of Annealing Process on Crystallinity and Structural Properties of Cotton/Spandex Fabric
}

\author{
Md. Nahid Pervez ${ }^{1,2,3}$, Md. Eman Talukder², Manoj Kanti Datta², Md Shipan Mia², Ashaduz Zaman², Meer Md Rasel Khan², \\ Yingjie Cai ${ }^{1,4}$ and Lina Lin ${ }^{1,5}$, a \\ ${ }^{1}$ Hubei Provincial Engineering Laboratory for Clean Production and High Value Utilization of Bio-based Textile Materials, Wuhan Textile \\ University, Wuhan 430073, China \\ ${ }^{2}$ School of Chemistry and Chemical Engineering, Wuhan Textile University, Wuhan 430073, China \\ ${ }^{3}$ Research Institute of Flexible Materials, School of Textiles \& Design, Heriot-Watt University, Galashiels TD1 3HF, UK \\ ${ }^{4}$ Engineering Research Centre for Clean Production of Textile Dyeing and Printing, Ministry of Education, Wuhan Textile University, Wuhan \\ 430073, China \\ ${ }^{5}$ College of Textile Science and Engineering, Wuhan Textile University, Wuhan 430200, China
}

\begin{abstract}
This research aims to elucidate the crystallinity, structural and mechanical properties of cotton/spandex knitted fabric after conducting heat setting i.e., annealing process with optimized condition for the first time. Experimental results disclosed that, crystallinity index (CI) (\%) of heat-treated cotton/spandex were increased with increased temperature and also mechanical properties i.e., tensile strength was improved as the temperature rose from 120 to $140^{\circ} \mathrm{C}$ and decreased with augmenting temperature ranges, which is in good agreement with the findings of CI $\%$ through X-ray diffraction (XRD) patterns. The attendance of cellulose dehydration was further confirmed by Fourier transform infrared (FT-IR) spectra in order to observe the structural integrity.
\end{abstract}

\section{Introduction}

Heat-setting (annealing) procedure, seen as an essential issue, is undertaken during the initial phase of the textile industry, considering the fact that it proffers the appropriate product's output to make it appropriate for additional steps and for the customer to utilise it $[1,2]$. Heat-setting, based on the report of Karmaker can be defined as a treatment that helps in imparting shape retention and crease resistance, as well as resilience and elasticity to the fibres, and also in causing change in strength and stretchability, as well as in softness dyeability, together with in crystalline structure, and in some occasions, on the material colour [3, 4]. There is a direct connection between the structural and chemical modifications taking place in the fibre and these changes. The ultimate loss of fabric dimensions is the result of under-setting, while power can be lowered as a result of over heat-setting, leading to spandex and companion fibres discoloration. Potential distortion or fabric deformation from residual uneven tension can be reduced by using the relaxation treatment leading to the power development and fabric recovery. The relaxation of the fabric should be performed prior to heat-setting so that marks and puckering during dyeing could be averted in order to see to it that the final garment's good dimensional stability is attained. Heat setting, apart from seeing to it that dimensional stability is imparted on the yarn and the fabric, is also important in some other areas,

\footnotetext{
a Corresponding author: linalin@wtu.edu.cn
}

such as the tendency for twisted or doubled filaments to possess the strength to curl or snarl, making such to have a harmful effect on additional processing. Heat setting, in every one of these operation, sometimes, accomplishes the basic objective in swelling agents and tension manifestation, specifically in taking the product toward equilibrium in order to see to it that resistance is attained against thermal shrinkage and dimensional changes, as well as in curling and creasing. It is possible for improvements to be attained in physical properties, specifically in mechanical properties [5]. In their work with polyester fibres [6,7], Gupta and Kumar made a comparison of slack and taut heat set yarns with regards to a non-heat set sample based in changes in their structures and mechanical properties. The range of temperatures was between 100 and $220^{\circ} \mathrm{C}$ while the period of exposure ranged between 1 and 60 minutes. It was discovered that there was increase in the level of crystallinity, or crystalline fraction as the heating temperature increased. It was also observed that changes in crystalline and amorphous phases using x-ray method was more, compared to density measurements. A very fascinating study undertaken by Kitano et al. [8] obtained the high crystalline percentage of $95 \%$ with PET fibre at high temperature. By measuring tensile properties, Venkatesh et al. [9] conducted an investigation on the mechanical properties of synthetic fibre changes as a result of heat setting. The structural behaviour of polymers is what determines their mechanical properties. 
The complex nature of polymers' structures is what made them to become a subject of much fascination. It is quite clear that there may be fundamental differences with regards to polymeric materials in many essential features based on how the preparation of the polymer was made. The possibility of obtaining technologically significant variations when it comes to structure and mechanical properties through varied crystallization and processing condition is well known [8]. The heat-setting procedure, generally, is undertaken above the transition temperature of the glass and lowers than the melting temperature for an appropriate time. Other important factors determining the heat-setting process's effectiveness and efficiency are the fabric width and overfeed. Type of impurities added during manufacturing of yarn and fabric, padding solution's wetting ability and the moisture in heat-setting chambers are among other factors [10]. These parameters are what the heat-setting process strongly depends on while just a small variation with regards to these limitations will have a huge effect on the properties of the fabric. So there must be careful selection, optimisation, and monitoring of these parameters.

In this paper, we made an introduction of heat treatment into the cotton/spandex blended fabrics in the form of its expertise for the structural behaviour accomplishment to be advanced and for the rising needs of industry to be met. Nonetheless, the investigation, so far conducted, with regards to heat treatment effect on crystallinity and cotton/spandex blended fabric structural properties, has been quite limited.

\section{Experimental}

\subsection{Materials}

For experimental work knitted single jersey fabrics with (1-5\%) spandex and 95\% cotton have been used. The fabric samples were knitted on Mayer and Cie (Germany) single knit machine by using 30/1 Ne cotton yarn and 24 denier spandex filament yarn and produced fabric had 74 course/inch, 38 wales/inch and fabric density of $276 \mathrm{~g}$ sq. $\mathrm{m}^{-1}$.

\subsection{Method}

The stenter machine (BRUCKNER, Germany) was used to carry out the heat setting process. At first, samples were placed between parallel bars at $10 \mathrm{~cm}$ length and stretched out to different degrees on an aluminium frame with pre-determined tension. There were six levels of temperature and time such as $(120,130,140,150,160$, $\left.170^{\circ} \mathrm{C}\right)$ and $(15,30,45,60,75,90 \mathrm{~s})$ respectively, while all other machine variables were held constant. Then, the process conditions were denoted as $\mathrm{C} 1, \mathrm{C} 2, \mathrm{C} 3, \mathrm{C} 4, \mathrm{C} 5$ and C6. After heat setting, the samples were cooled before being removed from the aluminium frame. Then the samples were conditioned under standard conditions of $65 \pm 2 \%$ relative humidity and $21 \pm 1^{\circ} \mathrm{C}$ for $24 \mathrm{~h}$.

\subsection{Measurement and characterization}

The tensile strength of samples was calculated according to our previous report [11]. The crystallinity behaviour of the samples was determined by using X-ray diffractometer (Shimadzu XRD-6000). The functional groups of treated samples were determined using a Fourier transform infrared (FTIR) spectroscopy (Bruker, United Kingdom) at the wavenumber range 500-4000 $\mathrm{cm}^{-1}[12,13]$.

\section{Results and discussion}

\subsection{Tensile strength}

The study of physical properties of fabrics is important due to apparel usually undergoes small extension and relaxation during wear and tensile strength is one of them [14]. Figure 1 shows the tensile strength values of the samples before and after under different heat-setting conditions. It can be seen that the tensile strength is increased after heat setting except for the sample number A1, as while it is decreased after heat setting. The highest tensile strength is shown in case of sample A3 and process condition $\mathrm{C} 3$ about $5 \%$ improvement compared to untreated sample and also there is little improvement about 3\% observed from sample A4 and A5. This result was attributed due to the fiber adhesion and fabric becomes stiffer during the heat setting [15] and also may be affiliated to the rearrangement of fibres after heat treatment which improved the tensile strength of the blended fabric [16]. Finally from these results it can be conclude that: (1) heat treatment at $140{ }^{\circ} \mathrm{C}$ results to increase tensile strength and (2) degradation in fabric starts at about $160^{\circ} \mathrm{C}$ which results to decrease in tensile strength. Sample A3 was chosen for further study.

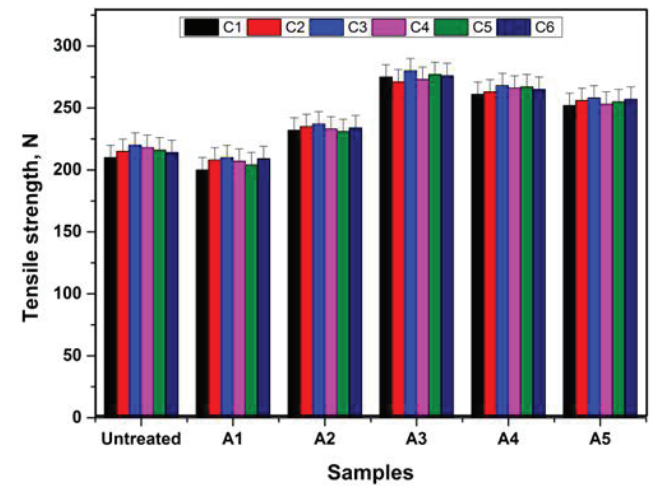

Figure 1. Tensile strength values.

\subsection{Crystallinity study}

The X-ray diffraction spectra of untreated and treated samples (A3) at various heat-setting conditions is presented in Figure 2. The results show that the untreated sample, which is the same as a semi crystalline polymer structure, presented some large and wide reflections due to its internal structure, and can be assigned according to the literature [17-19], with one significant peak appearing 
at $16.1^{\circ}$ with little crystallinity. As can be seen in Figure 2 , when the heat-setting condition surpassed $\mathrm{C}$, two peaks appeared that were (002) and (100). As the temperature increased, (002) peaks shifted from $19.58^{\circ}$ to $22.58^{\circ}$, then the $(100)$ diffraction peaks enhance. This result indicates that blended fabric is rearranged from disorderly to orderly and the crystalline structure improves remarkably with increasing temperature.

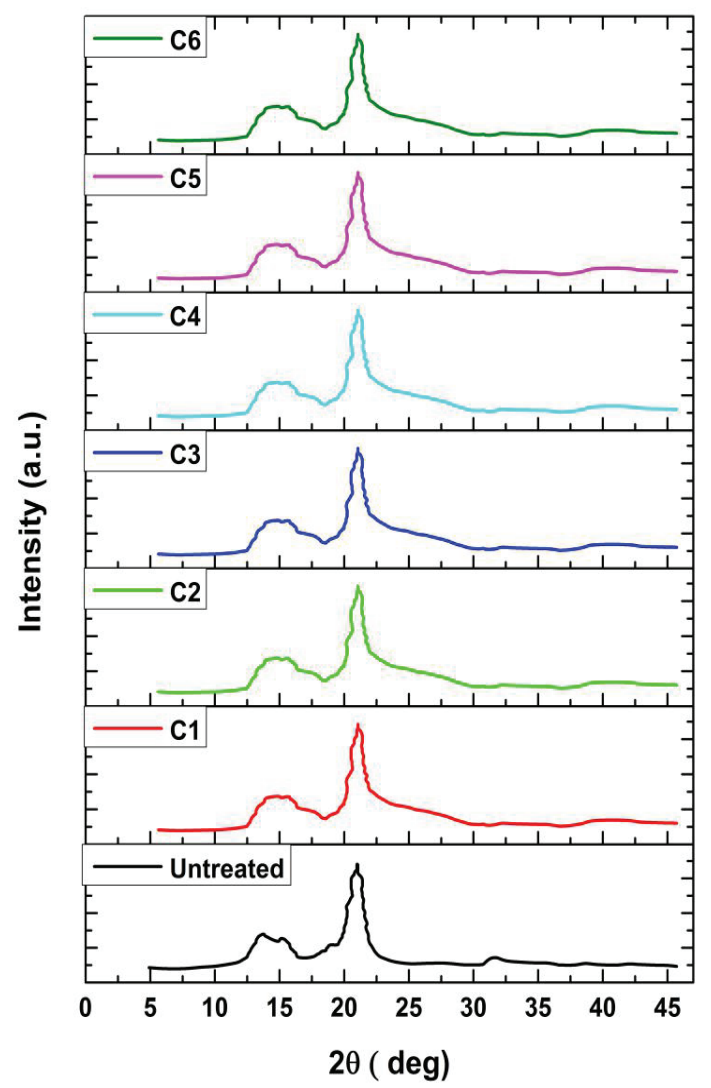

Figure 2. XRD spectra of sample (A3) at different heat setting condition.

From general literature, it can be demonstrated that the peak at $22{ }^{\circ} \leq 2 \theta \leq 23^{\circ}$ represents the characteristic height of cellulose I, which corresponds to the (002) crystallographic planes [20]. The crystallinity percentage for the untreated sample was found to be almost 3\%. The treated samples showed higher intensity for these peaks compared to the untreated samples, and this is due to the higher duration of heat setting temperature and the presence of spandex fibre acting as a nucleating agent. When annealing temperature at $140{ }^{\circ} \mathrm{C}$, the crystallinity percentage for blended fabric was observed up to $72 \%$, which is attributed due to; (1) at hygrothermal condition, cellulose molecules in the quasicrystalline region were easy to soften and began to rearrange or reorient [21]; and (2) during heat setting, the presence of free hydroxyl groups within the cellulose macromolecules are supposed to be involved in a number of intramolecular and intermolecular hydrogen bonds, which may result in various ordered crystalline arrangements [22]. In addition, the decomposition of the amorphous region of cellulose is also responsible for observing this phenomenon. This is supported through Basch and Lewin [23], who suggested that thermal decomposition of the cellulose initiated in the much less-ordered areas through demonstrating a drop inside the areas of polymerisation. It has been pronounced that the facilitated thermal decomposition of amorphous, as well as crystalline, regions changed following the dehydration reactions and other types of rearrangements of cellulose [24]. As far as the heatsetting process on the cotton/spandex is concerned, it may be stated that generally heat setting leads to a restructuring or recrystallisation with a higher degree of crystallinity and smaller crystallites with advanced orientation. In this recrystallisation process, at temperatures above $130{ }^{\circ} \mathrm{C}$, a considerable portion of the amorphous region is also transformed into crystalline regions [25]. The increase of the $\mathrm{CI}$ indicates the improvement in the cellulose structure and finally contributes to enhancing the tensile strength of the treated fibre, the results of which were verified by Figure 1. Moreover, at a later stage of the heat setting process, the amount of crystallinity percentage decreased due to continued degradation both in crystalline and noncrystalline regions. The higher numbers of chain scission reactions accelerated the amorphous character of cellulose, which reduced the total amount of cellulose crystalline regions [26]. Additionally, no free hydroxyl groups were involved in the reaction to generate hydrogen bonds.

\subsection{FT-IR analysis}

The FTIR spectra of untreated and treated samples (A3) at various heat-setting conditions in $500-4000 \mathrm{~cm}^{-1}$ region are presented in Figure 3. The cellulose characteristic bands, C-H stretching (3000-2700 $\left.\mathrm{cm}^{-1}\right)$ and $\mathrm{C}-\mathrm{H}$ wagging $\left(1429 \mathrm{~cm}^{-1}\right)$ bands, began to broaden at $120^{\circ} \mathrm{C}$ in untreated, whereas these bands remained stable at temperatures up to $170^{\circ} \mathrm{C}$ in blended fabric. Another substantial distinction was the development of the bands at $1645 \mathrm{~cm}^{-1}$ and $1605 \mathrm{~cm}^{-1}$, corresponding to $\mathrm{C}=\mathrm{O}$ stretching of unsaturated aldehydes and $\mathrm{C}=\mathrm{C}$ stretching of alkenes, respectively, which indicate the dehydration of cellulose [27,28]. These bands were intensified at 120$140^{\circ} \mathrm{C}$ for $\mathrm{C} 1-\mathrm{C} 3$ condition, and at $140-170^{\circ} \mathrm{C}$ for $\mathrm{C} 4-\mathrm{C} 6$ condition. The facilitated dehydration at lower temperatures was also supported by the early disappearance of C-O-C stretching $\left(1152 \mathrm{~cm}^{-1}\right)$ and $\mathrm{C}-\mathrm{O}$ stretching $\left(1020 \mathrm{~cm}^{-1}\right)$ bands. The shift of the $\mathrm{C}=\mathrm{C}$ stretching band toward $1585 \mathrm{~cm}^{-1}$, signifying conjugation of $\mathrm{C}=\mathrm{C}$ bonds, occurred at $120^{\circ} \mathrm{C}$, but no such shift was observed until the temperature reached $140^{\circ} \mathrm{C}$. Additional bands then appeared in $2000 \mathrm{~cm}^{-1}$ for C4-C6 treatment conditions that denoted its progressive dehydration of the cellulose in the range of $150-180{ }^{\circ} \mathrm{C}$, followed by the decomposition of the dehydrocellulose that could be formed through etherification between superimposed cellulose chains (C-2 and C-4) [29]. Since the shifts cause the bands to be closer to that of neat samples, it indicates that a reduction in the interaction of $-\mathrm{OH}$ groups with water molecules and dehydration of cellulose has occurred. However, at higher temperatures, the 
frequencies of the bands decrease slightly with increasing temperature.

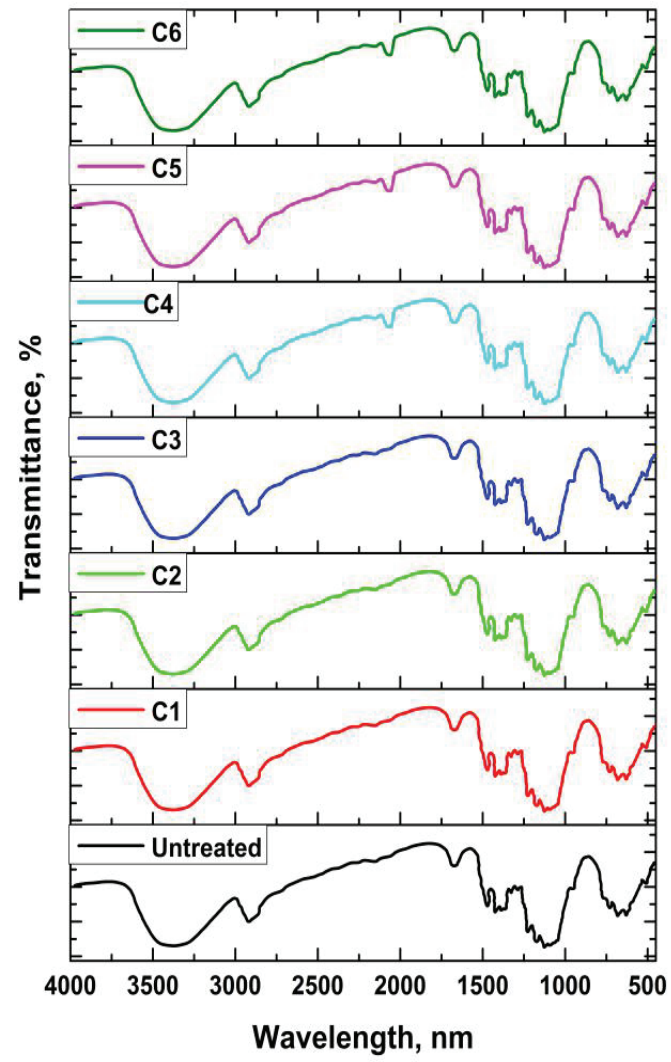

Figure 3. FT-IR spectra of sample (A3) at different heat setting condition.

\section{Conclusion}

Based on a series of experimental studies in this work, an analytical probe was performed to observe the annealing effect on crystalline, structural and mechanical properties in cotton/spandex knitted fabric. The samples were annealed in 120 to $170^{\circ} \mathrm{C}$ range and then subjected to regarding tests at room temperature. The tensile properties of cotton/spandex were significant improved by annealing treatment in the range of $120-140^{\circ} \mathrm{C}$. It was noted from XRD diffraction spectrum, heat treatment had no bright aftereffect on the position of the cellulose crystalline region. However, the crystallinity showed a gradual increase with heat- treated temperature increasing that was attributed to the heterogeneous nucleation effect.

\section{Acknowledgement}

This work was supported by the China National Textile and Apparel Council (2013 “Textile Vision" Applied Basic Research) a grant from the Hubei Province Science and Technology Support Program (Project 2013BAA043), and the Collaborative Innovation Plan of Hubei Province for Key Technology of Eco-Ramie Industry (E JIAO KE HAN 2014 No.8).

\section{References}

1. J. Gacén, D. Cayuela, J. Maillo, I. Gacén, J. Text. Inst. 93, 29 (2002)

2. M.A. Jahid, M.N. Pervez, American Journal of Materials Science and Technology 5, 57 (2015)

3. S.R. Karmakar, Chemical Technology in the Pretreatment Processes of Textiles (Elsevier Science, UK, 1999)

4. S. Mukhopadhyay, Advances in Fibre Science (Textile Institute, Manchester, 1992)

5. V.B. Gupta, J. Appl. Polym. Sci. 83, 586 (2002)

6. V.B. Gupta, S. Kumar, J. Appl. Polym. Sci. 26, 1865 (1981)

7. V.B. Gupta, S. Kumar, J. Appl. Polym. Sci. 26, 1877 (1981)

8. Y. Kitano, Y. Kinoshita, T. Ashida, Polymer 36, 1947 (1995)

9. G.M. Venkatesh, P.J. Bose, R.V. Shah, N.E. Sweltz, J. Appl. Polym. Sci. 22, 2357 (1978)

10. S.M. Desai, Colourage 58, 79 (2011)

11. M. Kamruzzaman, N. Pervez, E. Talukder, A. Kamal, Y.-J. Cai, Advances in Engineering Research, 103, 391 (2016)

12. M.N. Pervez, A. Khan, I.A. Khan, American Journal of Polymer Science \& Engineering 3, 90 (2015)

13. A. Khan, N. Pervez, I.A. Khan, S. Ahmad, R. Masood, T. Hussain, F. Telegin, Asian. J. Chem. 28, 1191 (2016)

14. C.W. Kan, Y.L. Lam, Materials 6, 314 (2013).

15. N. Furvik, A. Bernskiöld, N. Gralen, J. Text. Inst. Trans. 46, T662 (1955)

16. L. Wang, G. Cai, W. Yu, Synthetic Fiber in China, 31, 21 (2008)

17. N. Dencheva, Z. Denchev, M. J. Oliveira, S.S. Funari, J. Appl. Polym. Sci. 103, 2242 (2007)

18. Y.L. Lu, Y. Zhang, G.B. Zhang, M.S. Yang, S.K. Yan, D.Y. Shen, Polymer, 45, 8999 (2004)

19. E. Kaya, L.J. Mathias, J. Appl. Polym. Sci. 123, 92 (2012)

20. B.A. Ass, M.N. Belgacem, E. Frollini, Carbohyd. Polym. 63, 19 (2006)

21. M.T.R. Bhuiyan, N. Hirai, N. Sobue. J. Wood Sci. 46 431 (2000)

22. M. Poletto, A.J. Zattera, M.M. Forte, R.M Santana, Bioresour. Technol. 109, 148 (2012)

23. A. Basch, M. Lewin, J. Polym. Sci., Polym. Chem. Ed. 11, 3071 (1973)

24. G. Dobele, G. Rossinskaja, G. Telysheva, D. Meier, O. Faix, J. Anal. Appl. Pyr. 49, 307 (1999)

25. S. Sarkeshick, H. Tavanai, M. Zarrebini, M. Morshed, J. Text. Inst. 100, 128 (2009)

26. L. Kong, Z. Zhao, Z. He, S. Yi, Results Phys. 7, 914 (2017)

27. M. Tsuboi, J. Polym. Sci. 25, 159 (1957)

28. M.N. Pervez, F. Shafiq, M.M. Jilani, Z. Sarwar, Y.J. Cai, Materials Science Forum, 893, 71 (2017)

29. S. Nam, B.D. Condon, Y. Liu, Q. He, Polym. Degrad. Stabil. 138, 133 (2017) 